\title{
Efeitos da luminosidade no crescimento de mudas de Caesalpinia ferrea Mart. ex Tul. (Leguminosae, Caesalpinoideae)
}

\author{
Juliana Domingues LIMA, Breno Marques da Silva e SILVA² Wilson da Silva MORAES³, Vânia Andréa \\ Valente DANTAS ${ }^{4}$, Cilene Chaves ALMEIDA ${ }^{4}$
}

\begin{abstract}
RESUMO
Caesalpinia ferrea é uma espécie muito utilizada como planta medicinal e na arborização e paisagismo urbano no estado do Amapá. Entretanto, informações ecofisiológicas a seu respeito são escassas. A luz é um importante fator ambiental que controla processos associados ao acúmulo de matéria seca, contribuindo assim para o crescimento vegetal. Diante disso, estudou-se o efeito de diferentes níveis de luminosidade sobre o crescimento de mudas desta espécie. Para tal, plântulas foram repicadas para sacos plásticos contendo mistura de solo e areia (2:1), sendo mantidas a pleno sol, sob sombreamento artificial com redução de $50 \%$ e $70 \%$ da luminosidade e sob sombreamento natural de um dossel fechado de floresta. O delineamento experimental foi inteiramente ao acaso, com cinco repetiçôes. Mudas submetidas ao sombreamento natural tiveram seu crescimento fortemente inibido. A pleno sol, as mudas apresentaram maiores taxas assimilatórias líquida (TAL), menor razão parte aérea/raiz (RPAR) e menor razão de área foliar (RAF). Verificou-se pouca diferença no crescimento e alocação de biomassa entre mudas mantidas sob 50 e $70 \%$ de sombreamento, sendo que as mudas desses tratamentos atingiram valores mais altos de RPAR e RAF. Isto indica existência de plasticidade, o que reflete no aumento potencial da captura de luz, importante para manter o crescimento e a sobrevivência das mudas em baixa luminosidade. Em conjunto, os resultados mostraram ajustamento morfológico e fisiológico aos diferentes níveis de luminosidade em Caesalpinia ferrea.
\end{abstract}

PALAVRAS-CHAVE: Arbórea tropical, crescimento inicial, requerimento de luz, sombreamento.

\section{Effects of luminosity on the growth seedlings of Caesalpinia ferrea Mart. ex Tul. (Leguminosae, Caesalpinoideae)}

\begin{abstract}
Caesalpinia ferrea is a species used a lot as a medicinal plant, for urban arborization and landscape design in the state of Amapa. Yet there is not much ecophysiological information available on it. Light is an important environment factor that controls processes associates with the accumulation of dry matter, contributing thus for plant growth. The object of this research was to study the effect of different luminosity levels on the growth of seedlings of this species. The seedlings were transplanted to plastics bags containing a mixture of soil and sand (2:1), which were maintained in the full sun, under artificial shade with reduction of $50 \%$ and $70 \%$ of the luminosity and under natural shade of a closed canopy of forest. The experimental design was completely randomized with five replicates. Seedlings submitted to natural shade showed strong growth inhibition. In the full sun, the seedlings presented higher net assimilatory rate (NAR), lower shoot/root ratio (SRR) and lower leaf area ratio (LAR). The results showed little difference in the growth and biomass allocation between seedlings kept in 50 and $70 \%$ shade; the seedlings submitted to this treatment presented higher values of SRR and LAR. This indicates plasticity which influences a possible increase in light capture and is important, therefore, to keep the seedling growth and survival under low light levels. The results as a whole showed morphological and physiological adjustment to different light levels in Caesalpinia ferrea.
\end{abstract}

KEYWORDS: Tropical trees, Initial growth, Light requirements, Shading.

\footnotetext{
1 Profa. Assistente Dra., Campus Experimental de Registro, Universidade Estadual Paulista “Júlio de Mesquita Filho", UNESP, Rua Tamekishi Takano, n.5, Centro, Registro, SP, CEP 11.900-000. e-mail: judlima@registro.unesp.br

2 Doutorando, Faculdade de Ciências Agrárias e Veterinárias, Campus de Jaboticabal, Universidade Estadual Paulista "Júlio de Mesquita Filho", UNESP, Via de Acesso Prof. Paulo Donato Castellane, Jaboticabal, SP, CEP 14.884-900. e-mail: silvabms@fcav.unesp.br

${ }_{3}^{3}$ Pesquisador Dr., Pólo Regional do Vale do Ribeira, APTA, Av. Wild José de Souza, n.454, Centro, Registro, SP, CEP 11.900-000. e-mail: wilson@aptaregional.sp.gov.br

${ }^{4}$ Graduanda, Universidade Federal do Amapá, Rodovia JK, Km 02, Bairro Zerão, Macapá, AP, CEP 68.902-280.
} 


\section{INTRODUÇÃO}

Um dos principais problemas dos viveiristas ou produtores de mudas de espécies florestais é determinar os fatores que alteram a sobrevivência e o desenvolvimento inicial das mudas no campo durante a fase de enviveiramento, bem como as características fisiológicas da planta que melhor correlacionam com essas variáveis.

A formação de mudas mais vigorosas permite maior chance de sucesso no estabelecimento da cultura, bem como maximiza seu crescimento ao diminuir o tempo de transplante para o campo. Isto pode ser alcançado de maneira prática, rápida e fácil, observando-se parâmetros morfológicos (Fonseca et al., 2002) ou realizando análises do crescimento em mudas sob diferentes condições de luminosidade, nutrientes e água.

A luz, por ser fonte primária de energia relacionada à fotossíntese (Campos \& Uchida, 2002) e fenômenos morfogenéticos (Taiz \& Zeiger, 2004), é um dos principais fatores que influenciam o crescimento e o desenvolvimento dos vegetais. Todas as plantas têm habilidade para modificar o seu modelo de desenvolvimento em resposta ao ambiente luminoso (Holt, 1995). Todavia, a natureza da resposta morfogênica pode variar consideravelmente entre espécies de acordo com a capacidade de aclimatação e a dependência da quantidade ou qualidade da luz (Clough et al. 1980; Walters \& Field, 1987; Givnish, 1988; Seemann, 1992; Groninger $e t$ al., 1996; Taiz \& Zeiger, 2004). Desta forma, a eficiência do crescimento pode ser relacionada à habilidade de adaptação das mudas às condiçôes luminosas do ambiente, sendo o crescimento satisfatório de algumas espécies em ambientes com baixa ou alta luminosidade atribuído à capacidade da espécie ajustar rapidamente seu modelo de alocação de biomassa e comportamento fisiológico (Dias-Filho, 1997, 1999).

No estado do Amapá, Caesalpinia ferrea, conhecida por jucá, é uma espécie muito utilizada na arborização e paisagismo urbano, em função de suas características estéticas. Apresenta manchas claras no tronco, legumes lisos, duros e aromáticos contendo muitas sementes (Lorenzi, 1992). Apesar disso, informações ecofisiológicas a seu respeito são escassas.

Pelo exposto, o objetivo deste trabalho foi o de estudar os efeitos da luminosidade no crescimento de mudas de Caesalpinia ferrea.

\section{MATERIAL E MÉTODOS}

O estudo foi conduzido no viveiro de produção de mudas do Instituto de Pesquisas Científicas e Tecnológicas do Estado do Amapá (IEPA) em 2004, utilizando-se sementes provenientes de frutos de Caesalpinia ferrea, coletados de árvores nativas, provenientes do município de Porto Grande, AP.
No laboratório, as sementes foram retiradas dos frutos, escarificadas com lixa de papel e colocadas para germinar em areia lavada a $30^{\circ} \mathrm{C}$. Após a emergência, as mudas foram repicadas para sacos plásticos contendo $3 \mathrm{~kg}$ de mistura de solo de floresta de várzea e areia (2:1), suplementada com calcário dolomítico ( $31 \%$ de $\mathrm{CaO}$ e $18 \%$ de $\mathrm{MgO}$, com PRNT de 90,10\%, $3 \mathrm{~kg} / \mathrm{m}^{3}$ de solo) e NPK (4-14-8, $2 \mathrm{~kg} \cdot \mathrm{m}^{-3}$ de solo).

Trinta dias após a semeadura, dez mudas foram utilizadas para coleta de dados iniciais de crescimento para avaliação das variáveis, altura, número de folhas, área foliar e massa seca do caule, da raiz e das folhas. Em seguida, foram organizadas ao acaso em quatro grupos, distribuídos de acordo com o ambiente luminoso: 1 - pleno sol, $2-50 \%$ de sombreamento, 3- $70 \%$ de sombreamento e 4- sombreamento natural. Os níveis de 50 e $70 \%$ de sombreamento foram obtidos com telas de polietileno de cor preta, tipo sombrite, enquanto que o sombreamento natural foi obtido sob um dossel fechado de floresta, com redução de cerca de 86 a $89 \%$ da luminosidade. O delineamento utilizado foi o inteiramente ao acaso, com quatro tratamentos e cinco repetições, sendo que cada repetição foi constituída por dez mudas.

Posteriormente, foram avaliadas, periodicamente, as variáveis altura da planta, comprimento do último internódio, diâmetro do caule, número de folhas, área foliar, massa seca das folhas, massa seca do caule e massa seca da raiz. A área foliar foi determinada gravimetricamente, pelo peso do molde das folhas em papel, comparado à massa de um padrão com área conhecida, e a massa seca das folhas determinada após a secagem do material vegetal em estufa de circulação forçada de ar, a $70^{\circ} \mathrm{C}$, até peso constante.

A partir dos dados primários, variáveis subseqüentes foram determinadas: razão altura/diâmetro do colo (altura da planta/ diâmetro do colo), razão parte aérea/raiz (massa seca da parte aérea/massa da raiz), razáo de massa foliar (massa seca da folha/massa seca total), razão de área foliar (área foliar/massa seca total) e área foliar específica (área foliar/massa seca da folha). Também foram calculadas a taxa média de crescimento absoluto $\left(T C A=\left(\mathrm{P}_{2}-\mathrm{P}_{1}\right) /\left(\mathrm{t}_{2}-\mathrm{t}_{1}\right)\right.$, a taxa média de crescimento relativo da massa seca $\left(\mathrm{TCR}_{\mathrm{MS}},=\left(\ln _{2}-\ln _{1}\right) /\left(\mathrm{t}_{2}-\mathrm{t}_{1}\right)\right)$, a taxa de crescimento relativo da área foliar média $\left(\mathrm{TCR}_{\mathrm{AF}},=\left(\ln \mathrm{A}_{2}-\right.\right.$ $\left.\left.\ln A_{1}\right) /\left(t_{2}-t_{1}\right)\right)$ e a taxa média assimilatória líquida (TAL $=\left[\left(\mathrm{P}_{2}-\right.\right.$ $\left.\left.\left.\mathrm{P}_{1}\right) /\left(\mathrm{t}_{2}-\mathrm{t}_{1}\right)\right] /\left[\left(\ln \mathrm{A}_{2}-\ln \mathrm{A}_{1}\right) /\left(\mathrm{A}_{2}-\mathrm{A}_{1}\right)\right]\right)$, onde $\mathrm{P}=$ massa seca, $\mathrm{A}=$ área foliar e $\mathrm{t}=$ tempo, com índice ${ }_{1}=$ valor inicial e índice ${ }_{2}=$ valor final (Hunt, 1982).

Os dados experimentais foram submetidos à análise de variância e quando significativos, as médias foram comparadas pelo teste de Tukey a 5\% de probabilidade. 


\section{RESULTADOS E DISCUSSÃO}

Apesar do crescimento das mudas de Caesalpinia ferrea ter sido afetado pelas diferentes condiçôes de luminosidade testadas, cerca de $98 \%$ das mudas sobreviveram, observando-se mortalidade apenas no tratamento sombreamento natura.

As mudas submetidas ao sombreamento apresentaram menores áreas foliares e massa seca, quando comparado com as mudas cultivadas a pleno sol (Figuras 1 e 2). Resultados semelhantes também foram observados em outras espécies (Court \& Mitchell, 1989; Kwesiga \& Grace, 1986; Popma \& Bongers, 1988; Osunkoya \& Ash, 1991).

Aos 90 dias após a semeadura, o incremento da área foliar e o acúmulo de massa seca na raiz em mudas a pleno sol já se mostravam superiores aos demais tratamentos (Figuras 1A e 2C). Já os incrementos de massa seca total, massa seca na folha, massa seca no caule em mudas mantidas a pleno sol foram superiores aos demais tratamentos, apenas após 90 dias após a semeadura (Figuras 1B, 2A e 2B).

A área foliar pode ser considerada como um índice de produtividade, dada a importância dos órgãos fotossintetizantes na produção biológica da planta (Scalon et al., 2003). A expansão da folha sob baixa luminosidade é uma resposta freqüentemente relatada e indica uma maneira da planta compensar ou imprimir melhor aproveitamento à baixa luminosidade. Entretanto, em mudas de Caesalpinia ferrea,
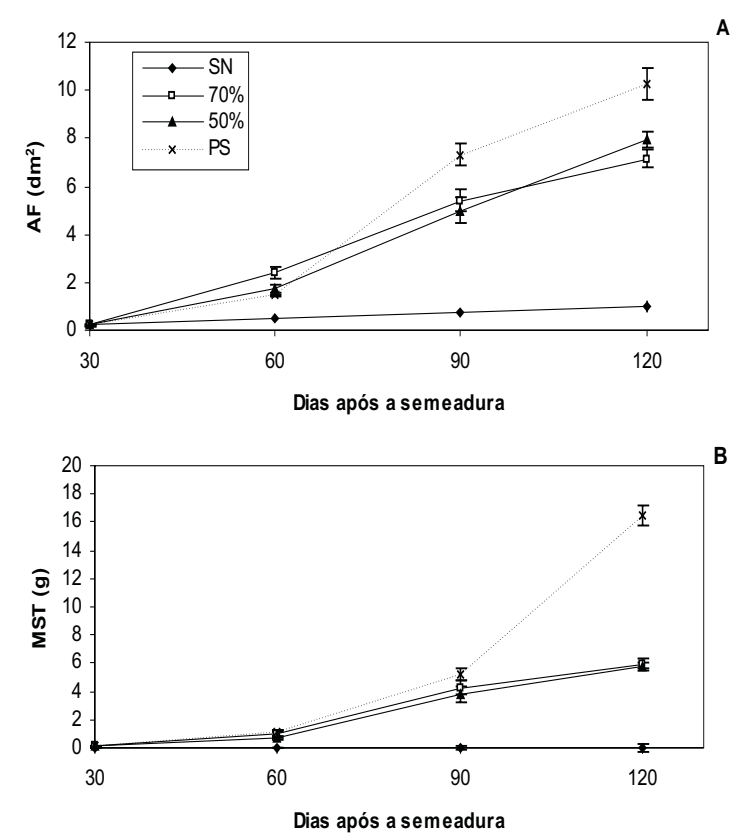

Figura 1 - Área foliar (AF) (A) e massa seca total (MST) (B) após a semeadura de mudas de Caesalpinia ferrea crescidas sob sombreamento natural (SN), $70 \%$ e $50 \%$ de sombreamento e pleno sol (PS). o aumento no sombreamento de 50 para $70 \%$ não resultou em incrementos da área foliar (Figura $1 \mathrm{~A}$ ).

Mudas mantidas sob sombreamento natural mostraram forte limitação de crescimento aos 60 dias após a semeadura, conforme dados da área foliar e acúmulo de massa seca total, de folhas, caule e raiz, provavelmente devido à baixa luminosidade e alterações na qualidade da luz (Figuras 1 e 2).

Não foram observadas diferenças significativas no incremento de área foliar, no acúmulo de massa seca total e na alocação da biomassa entre mudas sob 50 e $70 \%$ de sombreamento (Figuras 1 e 2).

Ocorreram poucas diferenças nas fraçōes de biomassa alocadas na folha, caule e raiz entre os tratamentos: pleno sol, $50 \%$ e $70 \%$ de sombreamento. Aos 120 dias após a semeadura, mudas cultivadas a pleno sol mostraram menor acúmulo de biomassa nas folhas e maior no caule, quando comparadas com mudas dos demais tratamentos (Figuras 3A, 3B, 3C e 3D).

As maiores alturas de mudas foram verificadas a pleno sol e as menores, sob sombreamento natural. Não houve estiolamento excessivo em mudas de qualquer tratamento. Entretanto, observou-se aumento do comprimento do último
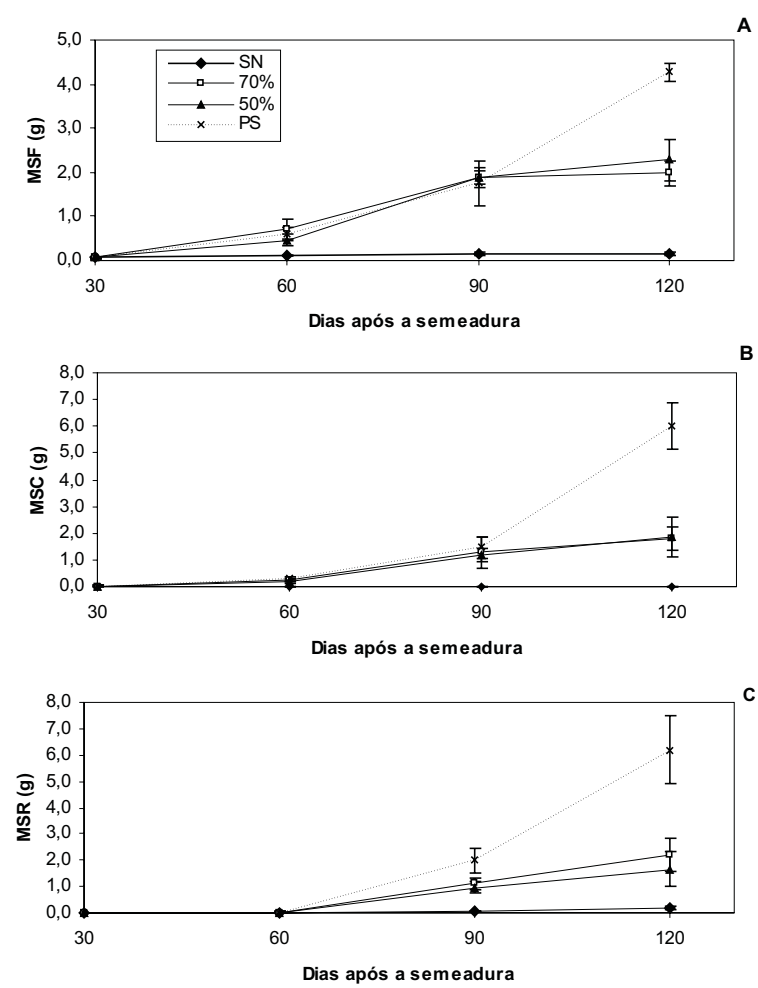

Figura 2 - Massa seca das folhas (MSF) (A), do caule (MSC) (B) e da raiz (MSR) (C) após a semeadura de mudas de Caesalpinia ferrea cultivadas sob sombreamento natural (SN), 70\% de sombreamento, $50 \%$ de sombreamento e pleno sol (PS). 

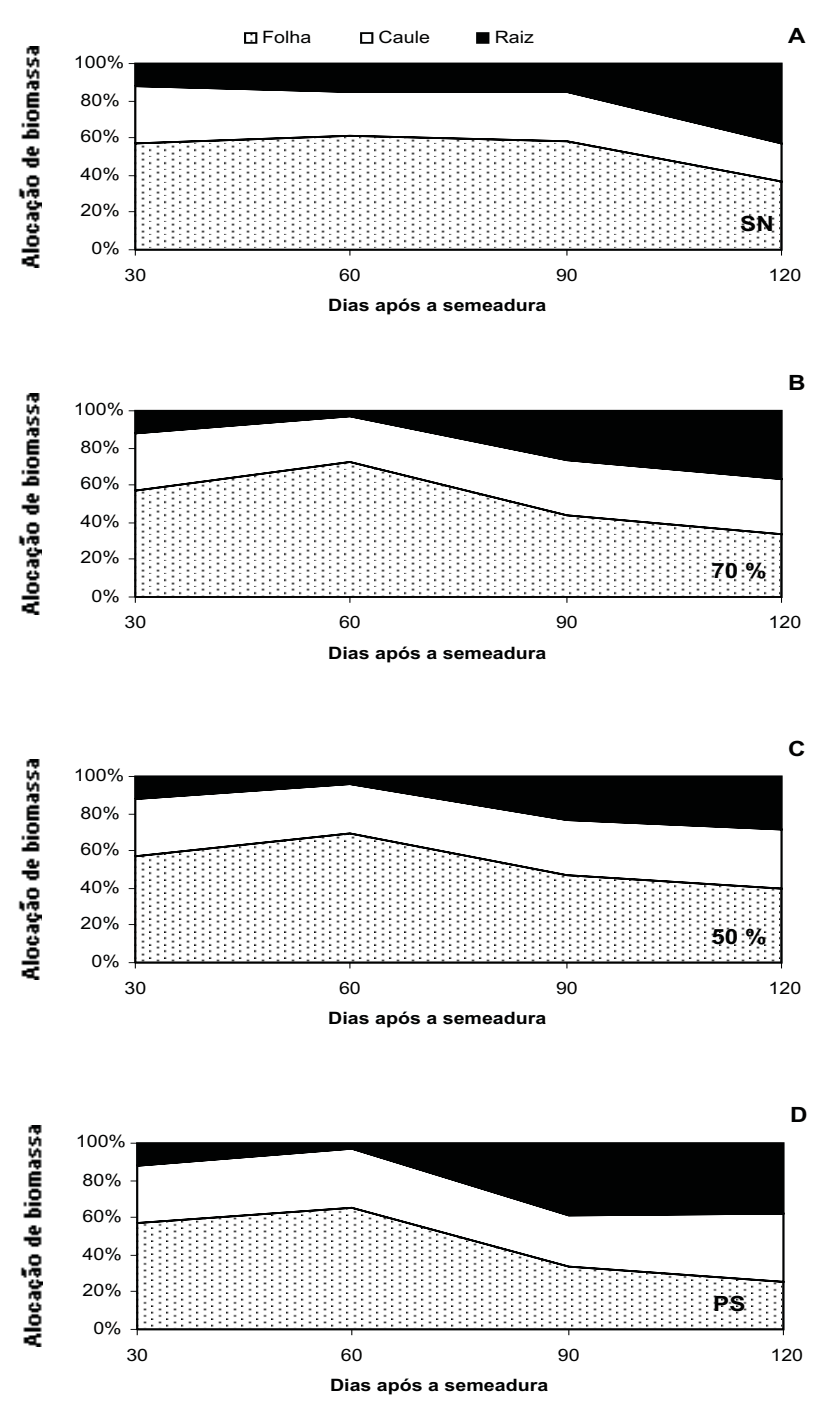

Figura 3 - Média da fração de alocação de biomassa em folha, caule e raiz, após a semeadura de mudas de Caesalpinia ferrea cultivadas sob: A - sombreamento natural (SN), B - $70 \%$ de sombreamento, C - $50 \%$ de sombreamento e D - pleno sol (PS).

internódio sob $50 \%$ e $70 \%$ de sombreamento, em relação às mudas sob pleno sol e sombreamento natural (Tabela 1).

O alongamento do internódio acompanhado pelo aumento de altura é uma reação comum em plantas submetidas ao sombreamento, pois segundo Smith \& Whitelam (1990), é uma resposta morfogênica típica. Entretanto, o aumento do comprimento do último internódio foi observado apenas sob 50 e $70 \%$ de sombreamento e não acompanhou o aumento da altura (Tabela 1). É possível, que no tratamento sob sombreamento natural a resposta morfogênica tenha sido limitada pela baixa produção de fotoassimilados, resultantes do cultivo sob baixa luminosidade (Souza \& Válio, 2003). De fato, Smith \& Hayward (1985) mostraram que a taxa de fotossíntese à baixa luminosidade pode limitar a capacidade da planta responder à baixa razão vermelho/vermelho distante, aumentando seu crescimento em altura.

O diâmetro do colo variou entre os tratamentos, havendo tendência de redução com o aumento do sombreamento. Boyer \& South (1984), também observaram influência da luminosidade no diâmetro do caule em Pinus taeda. Segundo Kozlowski (1962), o aumento do sombreamento diminui a fotossíntese e, conseqüentemente, a produção de fotoassimilados e reguladores de crescimento, causando redução no diâmetro do caule. $\mathrm{O}$ autor considera ainda que a fotossíntese, aparentemente, guarda uma relação mais direta com o crescimento em diâmetro do que com a altura da planta.

A razão altura/diâmetro do colo foi mais elevada em mudas submetidas a $70 \%$ de sombreamento, seguido de plantas a $50 \%$ de sombreamento e pleno sol, e reflete um maior crescimento em altura da parte aérea da planta em relação ao crescimento em diâmetro do caule (Tabela 1). A razão altura/diâmetro colo indica a qualidade das mudas a serem levadas ao campo, uma vez que se espera um equilíbrio no desenvolvimento (Campos \& Uchida, 2002).

O número de folhas apresentado pelas mudas aos 120 dias após a semeadura foi afetado significativamente pelo sombreamento. $\mathrm{O}$ maior número de folhas ocorreu em mudas mantidas a pleno sol, quando comparado com os demais tratamentos (Tabela 1).

Tabela 1 - Altura da planta (AP), comprimento do último internódio (CUI), diâmetro do colo (DC), número de folhas (NF), razão altura/diâmetro do colo (RADC), razão parte aérea/raiz (RPAR), razão de área foliar (RAF), área foliar específica (AFE) e razão de massa foliar (RMF) de mudas de Caesalpinia ferrea cultivadas sob sombreamento natural (SN), $70 \%$ de sombreamento, $50 \%$ de sombreamento e pleno sol (PS). Medidas feitas aos 120 dias após a semeadura.

\begin{tabular}{lccccccccc}
\hline & $\begin{array}{c}\text { AP } \\
(\mathrm{cm})\end{array}$ & $\begin{array}{c}\text { CUI } \\
(\mathrm{cm})\end{array}$ & $\begin{array}{c}\text { DC } \\
(\mathrm{mm})\end{array}$ & NF & RADC & RPAR & $\begin{array}{c}\text { RAF } \\
\left(\mathrm{dm}^{2} \mathrm{~g}^{-1}\right)\end{array}$ & $\begin{array}{c}\text { AFE } \\
\left(\mathrm{dm}^{2} \mathrm{~g}^{-1}\right)\end{array}$ & $\begin{array}{c}\text { RMF } \\
\left(\mathrm{g} \mathrm{g}^{-1}\right)\end{array}$ \\
\hline $\mathrm{SN}$ & $13,40 \mathrm{~d}$ & $3,84 \mathrm{c}$ & $1,58 \mathrm{c}$ & $9,60 \mathrm{c}$ & $8,48 \mathrm{c}$ & $1,35 \mathrm{~b}$ & $2,18 \mathrm{a}$ & $5,93 \mathrm{a}$ & $0,37 \mathrm{a}$ \\
$70 \%$ & $68,10 \mathrm{c}$ & $4,88 \mathrm{a}$ & $3,30 \mathrm{~b}$ & $18,6 \mathrm{~b}$ & $20,64 \mathrm{a}$ & $1,80 \mathrm{ab}$ & $1,20 \mathrm{~b}$ & $3,60 \mathrm{~b}$ & $0,33 \mathrm{a}$ \\
$50 \%$ & $61,96 \mathrm{~b}$ & $4,58 \mathrm{~b}$ & $3,38 \mathrm{~b}$ & $18,0 \mathrm{~b}$ & $18,33 \mathrm{~b}$ & $2,48 \mathrm{a}$ & $1,38 \mathrm{~b}$ & $3,48 \mathrm{~b}$ & $0,40 \mathrm{a}$ \\
\hline PS & $78,60 \mathrm{a}$ & $4,34 \mathrm{c}$ & $4,56 \mathrm{a}$ & $22,8 \mathrm{a}$ & $17,24 \mathrm{~b}$ & $1,66 \mathrm{~b}$ & $0,62 \mathrm{c}$ & $2,40 \mathrm{c}$ & $0,26 \mathrm{~b}$
\end{tabular}

Médias seguidas da mesma letra na coluna não diferem entre si, a $5 \%$ de probabilidade pelo teste Tukey.

As maiores razôes parte aérea/raiz ocorreram em mudas mantidas a $50 \%$ e $70 \%$ de sombreamento artificial, respectivamente (Tabela 1 ). Esses resultados, juntamente com valores mais baixos de massa seca da raiz, refletem menor acúmulo de biomassa na raiz de mudas sob sombreamento em relação a plantas mantidas a pleno sol (Tabela 1). Esse desequilíbrio pode ser prejudicial em termos de adaptação 
após o plantio no local definitivo, uma vez que mudas com sistema radicular bem desenvolvido têm maiores chances de sobrevivência no campo, especialmente, sob limitação de água. Possivelmente, o maior acúmulo de massa seca da raiz em plantas crescidas a pleno sol, deve-se a maior restrição hídrica, como relatado para Pinus taeda por Bongarten \& Teskey (1987).

A área foliar específica indica mudanças anatômicas ou morfológicas nas folhas, de tal maneira que o inverso da área foliar expressa diferenças na espessura foliar (Benincasa, 2003). Assim, os resultados de área foliar específica demonstram maior expansão da lâmina foliar sem um correspondente aumento da massa seca da folha, ou seja, uma redução na espessura da folha, à medida que se diminuiu a luminosidade (Tabela 1).

Mudas cultivadas a pleno sol apresentaram razão de massa foliar inferior àquelas cultivadas sob condições de sombreamento aos 120 dias após a semeadura, demonstrando maior intensidade de exportação de fotoassimilados da folha sob alta luminosidade. Não houve diferenças na razão de massa foliar entre mudas mantidas sob os diferentes níveis de sombreamento (Tabela 1).

Os valores da razão de área foliar tenderam a aumentar com a redução da luminosidade, não havendo diferenças na razão de área foliar entre mudas sob sombreamento de $50 \mathrm{e}$ 70\% (Tabela 1).

A taxa média de crescimento absoluto, a taxa média de crescimento relativo da massa seca e a taxa média assimilatória líquida foram mais altas em mudas submetidas a pleno sol, seguido de mudas mantidas a 70 e $50 \%$ de sombreamento, não diferindo entre si, mas, diferindo das taxas observadas em mudas submetidas ao sombreamento natural (Tabela 2). Em conjunto, essas variáveis indicam que quanto maior a luminosidade, maior a velocidade de crescimento, a taxa de acúmulo de massa seca e a fotossíntese líquida das mudas.

A taxa média de crescimento relativo da área foliar $\left(\mathrm{TCR}_{\mathrm{AF}}\right)$ dá a idéia da taxa de aumento da área foliar, demonstrando que não houve diferenças no aumento de área em mudas mantidas a pleno sol, 70 e $50 \%$ de sombreamento, e que mudas mantidas sob sombreamento natural apresentaram a menor taxa de aumento de área foliar (Tabela 2).

A aclimatação à variação de luminosidade é dependente da capacidade da planta em modificar tanto a alocação de massa seca como a capacidade fotossintética, de maneira a maximizar a assimilação do carbono na dada luminosidade (Osunkoya et al., 1994). Valores mais altos de razão parte aérea raiz e de razão de área foliar obtidos em mudas sob 50 e $70 \%$ de sombreamento mostram plasticidade. Esse fenômeno reflete um aumento no potencial para captura de luz, importante
Tabela 2 - Taxa de crescimento absoluto (TCA), taxa de crescimento relativo da matéria seca $\left(\mathrm{TCR}_{\mathrm{MS}}\right)$, taxa de crescimento relativo da área foliar $\left(\mathrm{TCR}_{\mathrm{AE}}\right)$ e taxa assimilatória líquida (TAL) de mudas de Caesalpinia ferrea cultivadas sob sombreamento natural (SN), $70 \%$ de sombreamento, $50 \%$ de sombreamento e pleno sol (PS). Medidas feitas no intervalo de 30-120 dias após a semeadura.

\begin{tabular}{lllll}
\hline & $\begin{array}{l}\text { TCA } \\
\left(\mathrm{g} \mathrm{dia}^{-1}\right)\end{array}$ & $\begin{array}{l}\mathrm{TCR}_{\text {MS }} \\
\left(\mathrm{g} \mathrm{g}^{-1} \mathrm{dia}^{-1}\right)\end{array}$ & $\begin{array}{l}\mathrm{TCR}_{\text {AF }} \\
\left(\mathrm{dm} \mathrm{dm}^{-2} \mathrm{dia}^{-1}\right)\end{array}$ & $\begin{array}{l}\mathrm{TAL} \\
\left(\mathrm{g} \mathrm{dm}^{-2} \mathrm{dia}^{-1}\right)\end{array}$ \\
\hline SN & $0,0039 \mathrm{c}$ & $0,0167 \mathrm{c}$ & $0,017 \mathrm{~b}$ & $0,008 \mathrm{c}$ \\
$50 \%$ & $0,0651 \mathrm{~b}$ & $0,0453 \mathrm{~b}$ & $0,038 \mathrm{a}$ & $0,033 \mathrm{~b}$ \\
$70 \%$ & $0,0630 \mathrm{~b}$ & $0,0449 \mathrm{~b}$ & $0,040 \mathrm{a}$ & $0,029 \mathrm{~b}$ \\
PS & $0,1822 \mathrm{a}$ & $0,0566 \mathrm{a}$ & $0,042 \mathrm{a}$ & $0,069 \mathrm{a}$ \\
\hline
\end{tabular}

Médias seguidas da mesma letra na coluna não diferem entre si, a $5 \%$ de probabilidade pelo teste Tukey.

para manter o crescimento e a sobrevivência das mudas em baixa luminosidade (Givnish, 1988).

Sob condiçōes de maior luminosidade, ou seja, a pleno sol, mudas de Caesalpinia ferrea apresentaram maior taxa assimilatória líquida e menor razão parte aérea raiz e razão de área foliar. O primeiro ajustamento (fisiológico), que ocorre com o aumento da TAL, reflete a capacidade da espécie em adequar seu aparelho fotossintético ao aumento da luminosidade. Os outros dois ajustamentos (morfológicos), que ocorrem com a diminuição da razão parte aérea raiz e razão de área, levam, no primeiro caso, a maximizar a absorção de água e nutrientes e, no segundo, a diminuição da demanda transpiratória em maiores luminosidades (Claussen, 1996).

A interpretação dos resultados obtidos deste estudo passa por conceitos relativos à tolerância e sucessão vegetal. Tais conceitos são básicos, tanto em relação ao manejo, como em relação à reposição florestal. Caesalpinia ferrea apresentou comportamento similar àquele encontrado para a maioria das espécies de florestas tropicais, ou seja, limitação nas condições de luminosidade do sub-bosque, mas com capacidade de manter, nestas condiçóes, a taxa de crescimento positiva. Isto se deve, provavelmente, à capacidade dessa espécie ajustar sua morfologia de modo a aumentar a captação de luz e potencializar seu crescimento com o aparecimento de clareiras, já que a espécie apresenta ajustamentos morfológicos e fisiológicos importantes para aclimatação à luminosidade mais alta.

\section{CONCLUSÃO}

As análises de variáveis biométricas indicam que a formação de mudas de Caesalpinia ferrea a pleno sol propicia melhores condições para o crescimento e o desenvolvimento. 


\section{BIBLIOGRAFIA CITADA}

Benincasa, M.M.P. 2003. Análise de crescimento de plantas: noções básicas. FUNEP, Jaboticabal. 41Ppp.

Bongarten, B.C.; Teskey, R.O. 1987. Dry weight partitioning and its relationships to productivity in loblolly pine seedling from seven sources. Forest Science, 33(3): 255-267.

Boyer, J.; South, D. 1984. A morphological comparison of greenhouse-grown loblolly pine seedlings with seedlings grown outdoors. Tree Planter's Notes, 16: 15-18.

Campos, M.A.A.; Uchida, T. 2002. Influência do sombreamento no crescimento de mudas de três espécies amazônicas. Pesquisa Agropecuária Brasileira, 37 (3): 281-288.

Claussen, J.W. 1996. Acclimation abilities of three tropical rainforest seedlings to an increase in light intensity. Forest Ecology and Management, 80: 245-255.

Clough, J.M.; Terri, J.A.; Alberte, R.S. 1980. Photosynthetic adaptation of Solanum dulcamara L. to sun and shade environments. III. Characterization og genotypes with differing photossynthetic performance. Oecologia, 44: 221-225.

Court, A.J.; Mitchell, N.D. 1989. The growth responses of Dysoxylum spectabile (Meliaceae) to a shaded environment. New Zealand Journal of Botany, 85: 955-963.

Dias-Filho, M.B. 1997. Physiological response of Solanum crinitum Lam. to contrasting light environments. Pesquisa Agropecuária Brasileira, 32 (8): 789-796.

Dias-Filho, M.B. 1999. Physiological responses of two tropical weeds to shade. I. Growth and biomass allocation. Pesquisa Agropecuária Brasileira, 34 (6): 945-952.

Fonseca, E.P.; Valéri, S.V.; Miglioranza, É.; Fonseca, N.A.N.; Couto, L. 2002. Padrão de qualidade de mudas de Trema micrantha (L.) Blume. produzidas sob diferentes períodos de sombreamento. Revista Árvore, 26 (4): 515-523.

Givnish, T.J. 1988. Adaptation to sun and shade: a whole-plant perspective. Australian Journal of Physiology, 15: 63-92.

Groninger, J.W.; Seiler, J.R., Peterson, J.A.; Kreh, R.E. 1996. Growth and photosynthesis responses or four Virginia Piedmont tree species to shade. Tree Physiology, 16 (9): 773-778.

Holt, J.S. 1995. Plant response to light: a potencial tool for weed management. Weed Science, 43: 474-482.

Hunt, R. Plant growth curves. 1982. The functional approach to plant growth analysis: Editora Edward Arnold, London. 247pp.
Kwesiga, H.; Grace, J. 1986. The role of the red/far-red ratio in the response of tropical tree seedlings to shade. Annals of Botany, 57: 283-290.

Kozlowski, T.T. 1962. Tree growth. The Ronald Press, New York, p.149-170.

Lorenzi, H. 1992. Arvores Brasileiras: manual de identificação e cultivo de plantas arbóreas nativas do Brasil. Editora Plantarum, Nova Odessa. 352pp.

Osunkoya, O.O.; Ash, J.E. 1991. Acclimation to a change in light regime in seedlings of six Australian rainforest tree species. Australian Journal of Botany, 39: 591-605.

Osunkoya, O.O.; Ash, J.E.; Hopkins, M.S.; Graham, A.W. 1994. Influence of seed size and seedling ecological attributes on shadetolerance of rain forest tree species northern Queesland. Journal of Ecology, 82: 149-163.

Popma, J.; Bongers, F. 1988. The effect of canopy gaps on growth and morphology of seedlings of rain forest species. Oecologia, 75: 625-632.

Scalon, S.P.Q.; Mussury, R.M.; Rigoni, M.R.; Scalon Filho, H. 2003. Crescimento inicial de mudas de Bombacopsis glabra (Pasq.) A. Robyns sob condição de sombreamento. Revista Árvore, 27 (6): 753-758.

Seemann, J.R. 1992. Light adaptation/acclimation of photosynthesis and the regulation of ribulose-1,5-bisphosphate carboxylase activity in sun and shade plants. Plant Physiology, 91: 1-18.

Smith, H.; Hayward, P. 1985. Fluence rate compensation of the perception of red:far ratio by phytochrome in light-grown seedlings. Photochemistry and Photobiology, 42: 685-688.

Smith, H.; Whitelam, G.C. 1990. Phytochrome, a family of photoreceptors whith multiple physiological roles. Plant Cell and Environment, 13: 695-707.

Souza, R.P.; Válio, I.F.M. 2003. Seedling growth of fifteen Brazilian tropical tree species differing in successional status. Revista Brasileira de Botânica, 26 (1): 35-47.

Taiz, L.; Zeiger, E. 2004. Fisiologia Vegetal, 3. ed. Artmed, Porto Alegre. 719pp.

Walters, M.B; Field, C.B. 1987. Photosynthetic light acclimation in two rainforest Piper species with diferent ecological amplitudes. Oecologia, 72: 449-456.

Recebido em 11/10/2006

Aceito em 31/08/2007 